\title{
Cartas Sororales entre de dos mujeres intelectuales: Palma Guillen y Gabriela Mistral
}

\author{
Sorority letters between two intellectual women: \\ Palma Guillén and Gabriela Mistral
}

Oresta LÓPEZ PÉREZ1

\begin{abstract}
Resumen
En el presente trabajo hacemos una inmersión al tejido epistolar como la figuración de la sororidad entre dos grandes maestras latinoamericanas: la escritora chilena y premio Nobel Gabriela Mistral y Palma Guillén, maestra mexicana, diplomática y escritora. Una relación que inició en 1922 y duró hasta la muerte de Gabriela Mistral en 1957. Especialmente se revisará el intercambio epistolar entre 1942 y 1957, (ZIEGERS, 2011), para posicionar los alcances, disidencias y aportes de la comunicación entre mujeres, como representación sororal. Las fuentes son las cartas tejidas en la comunicación que en esta época podían construir dos grandes amigas, enfrentando a su manera las distancias, la desesperación, el dolor personal y las percepciones del mundo en guerra que vivieron.
\end{abstract}

Palavras-clave: Sororidad. Género. Escritura capitular. Educación.
Abstract

Sorority letters between two intellectual women: Palma Guillén and Gabriela Mistral In the present work an immersion in the epistolary exchange is offered as the figuration of the sorority between two great Latin American women intellectual: the Chilean woman writer and winner of the Nobel prize Gabriela Mistral, and Palma Guillén, woman diplomat and Mexican writer. A relationship that began in 1922 and lasted until the death of Gabriela Mistral in 1957. I analyze the epistolary exchange between 1942 and 1957 (Ziegers, 2011) looking for cognitive possibilities of sororal representation, to know the meanings, dissidences and contributions about communication between women. The sources are the text woven in the communication between two great women friends who face in their own way the distances, the desperation, the personal pain and the perceptions of the world in the wars they lived.

Keywords: Sorority. Gender. Capitular writing. Education.

1 Dra. en Ciencias Sociales, Profesora Investigadora de El Colegio de San Luis, Centro Público de Investigación del Consejo Nacional de Ciencia y Tecnología de México. Coordinadora del Laboratorio de Investigación: Género Interculturalidad y Derechos Humanos LIGIDH-COLSAN www.colsan.edu.mx tel. (52)-444-8110101 ext.6112. E-mail: <oresta.lopez@colsan.edu.mx>.

\begin{tabular}{l|l|l|l|l|l|} 
R. Educ. Públ. & Cuiabá & v. 28 & n. 67 & p. 151-168 & jan./abr. 2019 \\
\hline
\end{tabular}


Nadie como la maestra y escritora chilena Gabriela Mistral (1897-1957), encontró en el género capitular, desde muy pequeña, un bálsamo para la timidez y para la soledad. Como a tantas mujeres educadas de principios del siglo XX, las cartas le permitieron no solo expresar, sino construir sus pensamientos y sus sentimientos, construirse una identidad. Las cartas por ello son parte de la construcción reflexiva de la realidad emocional de las mujeres. ${ }^{2}$ Para una escritora como ella, la escritura lo era todo, las cartas le permitían poner en muchas partes del mundo sus pensamientos y sus emociones, quizá más difícilmente expresadas en forma oral y cara a cara.

Vivió un intenso amor por cartas con Fernando Magallanes, por más de siete años. Las cartas eran olidas y guardadas, le hacían sentir el fuego con solo tocarlas en el bolsillo, decía.

Vivía para escribir y leer cartas, estando en la Patagonia en su periplo de maestra escritora y luego por todo el mundo, como una verdadera patiloca, siempre estuvo bien conectada con los suyos, a través de las cartas.

Especialmente con sus amigas, acompañantes (Laura Roding, Palma Guillén, Consuelo y Doris Dana), mal llamadas secretarias, compartía vínculos poderosos y hasta "sentimientos extraños", plasmados a través de cartas, que leía hasta tres veces o más, eran un bálsamo para la ausencia, eran las que le permitían incluso sobrellevar los últimos años de su vejez y enfermedad, en New York.

\section{Gabriela y lo epistolar}

Las cartas como una práctica específica de escritura constituyen una historia de la sociabilidad a través de las mediaciones de la escritura. Autoras como Patrizia Violi afirman que es una práctica que pone de manifiesto la ausencia, del interlocutor, es una especie de diálogo diferido que destaca por construir al ausente mediante reconstrucciones imaginarias, dado que la escritura sucede en un tiempo y en un lugar distintos. Finalmente existe una tensión entre la realidad y la verdad histórica del sujeto o actor social auténtico, y la representación discursiva, una realidad pasada por las mediaciones del actor que escribe. Son dice Violi "verdaderos simulacros de una realidad pasada por el filtro del individuo". (Violi, 1987; 89).

2 Castillo, Darcie Doll. (2000). El discurso amoroso en las cartas de Gabriela Mistral. Revista signos, 33(47), 11-23. <https://dx.doi.org/10.4067/S0718-09342000000100002> 
En este sentido Gabriela Mistral, como autora de cartas, se convirtió desde muy joven en una gran experta del género capitular. Tuvo una reflexividad e introspección constante a partir de cartas privadas. Escribía mucho a sus más cercanos amigos, a sus seres queridos y a otras muchas personas de otras partes del mundo. No solo fue un medio para socializar, sino que sus cartas tienen elaboraciones escriturales muy suyas, pues modela y construye la presencia del interlocutor ausente, con gran maestría. En sus cartas hay un trabajo de creativa intimidad con las ausencias, hay narrativas intensas con variados detalles que ofrecen etnografías del viaje, etnografías del deseo y etnografías emocionales muy variadas. Hay textos y contextos, que retan a la interpretación rigurosa, así como la enunciación de pactos de escritura e intersubjetividades implícitas muy complejas.

En este trabajo haremos una aproximación al tejido epistolar sostenido entre la escritora con su amiga mexicana, Palma Guillén. Una relación que inició en 1922 y duró hasta la muerte de Gabriela Mistral en 1957, continuando posteriormente con Doris Dana. Será esta temporalidad el contexto temporal de nuestro análisis, aunque en forma específica se revisarán las cartas que Palma escribió a Gabriela entre 1942 y 1957, por ser estas públicas (Zegers, 2011).

\section{Palma y Gabriela}

Pese a ser muy conocida la relación entre Palma y Gabriela, de la primera se sabe muy poco. ${ }^{3}$ De tal modo, que aparece a la sombra de Gabriela, enunciada como la secretaria asignada a la escritora, la Palmilla en la correspondencia mistraliana. Se trata de una imagen que choca con la historia deseable por las feministas mexicanas, es decir la Palma de Gabriela es servicial, maternal, una hermana mayor que está dispuesta a dedicar su vida y su tiempo al cuidado y confort de los otros. Palma cuidó de Gabriela desde el momento mismo en que la conoció y aún más allá de su muerte. Ordenaba por igual su correspondencia, que editaba textos o hacía gestiones consulares y notariales, cocinando o cuidando de la crianza del hijo adoptivo de Gabriela y aún después de fallecida la escritora, se seguía ocupando de poner en orden asuntos de sus propiedades y el cuidado de su honor, o atendiendo pendientes editoriales. Gabriela también se preocupaba por Palma, usando un tono de proveedora, aparece como solidaria en gastos y herencias. Esa relación aparece en el tejido epistolar.

3 La Dra. Gabriela Cano, una de las biógrafas de Palma Guillén, señala que reconstruir su biografía es una empresa muy difícil. 
Palma Guillén, (1898-1975) era profesora de materias de lógica, literatura, psicología y Gabriela profesora en Liceos de niñas daba cursos de Lengua Castellana y de Geografía. Palma a casi diez años de la muerte de Gabriela, analizó nuevamente su encuentro con Gabriela, en 1966, cuando reescribió la presentación a las Lecturas para mujeres de GM., ahí reconoce que se vio entonces como una chica presumida frente a Gabriela, era imponente la poeta, por ello: "Confieso que la misión no fue muy fácil. Gabriela era una persona de formación muy diversa de la mía. Sabía mucho y de muchas cosas y todo lo había aprendido por sí misma, sin escuela ni maestros". ${ }^{4}$

Palma también se interesó en la diplomacia y fue una de las primeras mujeres mexicanas en representar a México en labores consulares. Perteneció al grupo de intelectuales de la Universidad Nacional, que colaboraban en la gran obra de Vasconcelos cuando este fue nombrado ministro de educación por el Presidente Álvaro Obregón.

El Vasconcelos de ese momento era gigante en las memorias de Palma:

José Vasconcelos había echado a andar la gran máquina de la Secretaría de Educación -poca herramienta, en aquellos años, y mucho espíritu- y todos los jóvenes de entonces íbamos con él llenos de entusiasmo. Éramos su equipo de trabajo, las manos con las que él abría, alegremente, sendas nuevas en el ambiente de México. ${ }^{5}$

Palma relataba que Vasconcelos la eligió para acompañar a Gabriela, para mostrarle el mundo educativo rural y presentarla en México. Era la anfitriona par de Gabriela, no la "secretaria" asignada. ${ }^{6}$ Palma relata las motivaciones del Ministro al elegirla para tal tarea:

[...] cuando Vasconcelos supo que Gabriela había aceptado la invitación que nuestro Gobierno le hizo a través de nuestra Legación en Chile, me llamó y me dijo: -"Palmita, va a llegar Gabriela Mistral. Viene a trabajar con nosotros. Yo quiero que conozca bien a México. Quiero que vea lo

4 Palma Guillen, presentación en Gabriela Mistral, Lecturas para mujeres, SEP, México 2a reimpresión, 1988.

5 Ibid.

6 Palma afirma: "Mucha gente dice que yo fui secretaria de Gabriela. No, su secretaria fue Eloísa Jaso, que aún vive, la hermana de la gran maestra Carlota Jaso.” presentación en Gabriela Mistral, Lecturas para mujeres, SEP, México 2a reimpresión, 1988. 
bueno y lo malo que tenemos aquí, lo que estamos haciendo y lo que nos falta... ¿ ¿Usted sabe quién es Gabriela Mistral?” (Yo sabía muy poco - puedo decir honradamente que no sabía nada de Gabriela Mistral ... Había leído en alguna revista los Sonetos de la Muerte; pero no estaba enterada de las ideas pedagógicas, sociales y otras de Gabriela, ni sabía lo que ella significaba, ya desde entonces, en el Continente... ) -"Ella tiene muy buenas ideas sobre la educación. Es una mujer de la provincia, casi del campo, y sabe lo que necesita la gente del campo. Es una gran maestra y una gran poetisa. He pensado mucho a quién puedo confiársela aquí para que la acompańe y la guíe. No quiero que tenga una visión equivocada o parcial de México. No quiero que la hagan ver sólo lo bueno o sólo lo que le interese a la persona que la guíe. Yo quiero que Gabriela lo vea todo, que nos dé su opinión acerca de todo lo que estamos haciendo y que nos ayude con su experiencia y con su intuición. Es una mujer genial, admirable. Pienso que Ud., que es menos doctrinaria que Fulana y menos especializada que Zutana, podría ser más útil para esta misión. Ud. viajará con ella, le hará conocer el país: lo bello y lo feo, lo bueno y lo malo, la capital y la provincia -el campo sobre, todo-, la Universidad y la escuela rural, etc. ${ }^{7}$

Era para Gabriela el primer viaje largo al extranjero, era un viaje apoyado por las instituciones de gobierno e iba acompañada de dos colaboradoras chilenas, Palma recuerda que la famosa poeta no era lo que ella imaginaba, fue cuando ella aprendió a leer los ojos de Gabriela:

Gabriela Mistral llegó en un barco que la trajo de su lejana tierra. Fuimos a recibirla al puerto, en nombre de la Secretaría, Jaime Torres Bodet y yo. No sé la impresión que Gabriela hizo a Jaime Torres Bodet. A mí, que era una muchacha presumida, me pareció mal vestida, mal fajada, con sus faldas demasiado largas, sus zapatos bajos y sus cabellos recogidos en un nudo bajo. Veo los ojos temerosos de Gabriela. Aquellos ojos, casi siempre cubiertos por los párpados caídos, tenían dos modos de mirada: una mirada rápida y relampagueante en la que podía estar el

$7 \quad$ Ibid. 
encantamiento, la sorpresa, la cólera o el temor -muy frecuentemente el temor- y una mirada serena, sostenida, que era como un agua encantada, como una agua verde con mucha luz adentro: la mirada de la confianza, de la comprensión, del reposo; pero, la mayor parte del tiempo, sus ojos eran como pájaros asustados. ${ }^{8}$

Qué tenían en común estas mujeres además de ser interlocutoras y admiradoras de José Vasconcelos? Al respecto dirá Palma, que tenían más bien diferencias. Palma era de naturaleza urbana y se autodenominaba como una seńorita presumida, bien vestida y moderna. Mientras que Gabriela, era de naturaleza rural, era una campesina ilustrada, proveniente de un pueblito minúsculo perdido en el norte de Chile, del cual no se tenía mayor referencia. Gabriela no mostraba interés en destacar su femineidad, era más bien como una monja pobre. Tenían el carácter muy diferente y de diferentes geografías y oscuridades, Palma siempre fue tolerante y gentil:

De carácter, sobre todo, éramos muy diversas: ella, mujer de la montańa, yo, mujer del altiplano. En Gabriela había muchas zonas oscuras, honduras y misterios -aquello que sabía de "ceniza y firmamento", / "..mi flanco lleno de hablas y mi flanco de silencio, y lo que supe, temblando, de manantiales secretos...",/ oscuras cosas que yo no comprendí al principio o que no comprendí nunca; pero que supe respetar siempre. La cortesía que, dígase lo que se diga, es una virtud, puesto que consiste en darse cuenta de que los demás existen y en respetarlos, me sirvió grandemente en el primer tiempo. ${ }^{9}$

Así, juntas recorrieron muchos lugares de la amplia geografía mexicana, hubo sitios a los que volvían, se hicieron unas grandes viajeras y compañeras de viaje, la misma alma disfrutó y aprendió día a día de ese primer periplo mexicano:

Me veo en el tren, con ella, de un lado para otro: Pachuca, El Chico, Cuautla, Cuernavaca, Puebla, Zacapoaxtla, Atlixco, Taxco, Pátzcuaro, Zamora, el Cañón de Tomellín, Oaxaca, Acapulco, Guadalajara, Querétaro, Veracruz. . .

8 Ibidem.

9 Ibidem. 
Sol, polvo, calor. Escuelas instaladas en viejos curatos, en patios, en solares, en casas particulares, casi sin muebles. Llegábamos en tren o en los camiones de la Secretaría -a veces dormíamos en ellos ... ${ }^{10}$

Tenían conversaciones interminables en las que también participaba la madre de Palma, y hasta se llegó a quedar a dormir en su casa. Intimaron, se familiarizaron, se quisieron como hermanas. Palma señala que su contacto con Gabriela la enriqueció, le volvió los ojos a la América Latina en tiempos en que casi todos los intelectuales mexicanos miraban a Europa y a Estados Unidos:

Ella estaba centrada en la América y aunque se hubiera leído, traducidos al español, a muchos escritores clásicos y modernos, era la América, la América Latina, la que le importaba. Yo estaba más cerca de Europa y, sobre todo de Francia, que, de Colombia o la Argentina y sabía más de Homero, de Lucrecio, de Schopenhauer o de Bergson que de Miranda, Sarmiento o Rodó, aunque hubiera hecho mis cursos de literatura hispanoamericana con el gran maestro Pedro Henríquez Ureña y aunque me supiera de memoria muchos versos de Darío y de José Asunción Silva. Además, ella era un gran poeta y los grandes poetas se mueven en una atmósfera que a veces ahoga a los simples mortales. ${ }^{11}$

Gabriela cargó en el barco con todos sus libros porque iba lista para hacer una antología de lecturas para mujeres. Encargo que cumpliera en medio de críticas y desavenencias con la intelectualidad literaria y normalista, eran momentos de intenso nacionalismo y ella fue tratada como extranjera. Le cuestionaban a Vasconcelos el honor de hacer una escuela que llevara su nombre y que le encargarán hacer una antología de lecturas y peor aún, que hicieran una estatua de la maestra. Palma recuerda:

Hubo, personas que empezaron a hacer críticas y comentarios malévolos. -”...¿Qué venía a enseñar, que no supiéramos ya, esa 'extranjera'? ¿Qué novedades había traído? Aquí había muchos buenos maestros y cualquiera de ellos podría hacer en la provincia lo que hacía Gabriela... ${ }^{12}$

10 Ibidem.

11 Ibidem.

12 Ibidem. 
Adolorida Gabriela terminó su visita para ir a los Estados Unidos, Palma afirma que trataba de ocultarle las malas noticias, pero se enteró y ella que tanto amaba a México, se sintió tratada como una extranjera. Gabriela amaba a México desde antes de conocerlo y durante su estancia, lo amó más. Se reunía con campesinos, con maestros con cuantos pudiera. La escuchaban con un fervor casi religioso. Gabriela tenía el don de la palabra y un gran conocimiento de la vida rural, ayudaba con recomendaciones pedagógica y abonaba los corazones con su poesía, su prosa y su etnografía permanente.

Las actitudes xenófobas acabaron por bajarle los ánimos y Palma fue testiga del dolor que le causaban esos comentarios:

Yo sé bien lo que le dolió sentirse "la extranjeras", llamarse a sí misma "la extranjera" en este país que amó tanto como al suyo y del que quería ante todo ser amada. La Introducción escrita por ella es una admirable presentación y exposición del libro en la que Gabriela desarrolla, sus ideas acerca de la educación en general y acerca de la educación de la mujer en particular; pero es también una respuesta llena de dignidad, a las críticas y a las ofensas que le hicieron, En ella casi se excusa de haber venido a trabajar entre nosotros y para nosotros -ella que, dentro de su hispanoamericanismo verdadero y total, soñó siempre con una América Latina sin fronteras en la que el pensamiento y el trabajo pudieran circular libremente para bien y alegría de todos. Firma con las palabras $L a$ Recopiladora, sin poner su nombre, para disminuirse como la disminuían y para quitarle importancia a la obra en la que la décima parte, cuando menos, del material tan novedoso como bien escogido está formado por textos suyos, escritos muchos especialmente para este libro. ¡Pobre Gabriela, tan maltratada, tan injustamente atacada y tan sola siempre!. ${ }^{13}$

Palma entabló una relación profunda con Gabriela Mistral, nunca más dejaron de estar en contacto, incluso se llegaron a llamar mutuamente carińosamente "hijitas". Se escribieron cartas a lo largo de toda su vida. Incluso su primera obra publicada de poesía, Tala, fue dedicada a Palma.

Con Gabriela estuvo en diferentes momentos de grandeza y de profunda tristeza. Uno de los lazos íntimos más significativos, fue sin lugar a dudas, compartir legal y cotidianamente la crianza y responsabilidad formal de Luis Miguel Godoy, hijo adoptivo a quien llamaban Yin Yin.

13 Palma Guillen, 1966. 
Palma sería su brújula en el mundo de los viajes y de las relaciones consulares, sería la que fue educada para socializar y la que además siendo bien avezada en francés, era también buena editora de sus textos y una fiel muy fiel acompañante en los periplos mistralianos por el mundo europeo y de la diplomacia.

Había entre ellas una hermandad sororal ${ }^{14}$ llena de ternura e incondicionalidad, eran amigas intimas, madres-cómplices de la educación de Yin Yin, camaradas pacifistas, activistas antifranquistas y a ratos socias. Palma la infaltable para soportar el mal carácter y las oscuridades de la poeta, las constantes depresiones y amarguras de la controvertida Gabriela.

No entraremos aquí a discutir la vida sexual en el subconsciente de nuestros personajes, pues se ha hecho mucho ruido a partir de las cartas, afirmando que Gabriela era una lesbiana tardía y que fue la Queer mother de América. ${ }^{15}$ Aunque la soledad de Gabriela es muy transparente, no es fácil llegar a comprender su sexualidad, pero es cierto que en sus cartas y poemas, existe el discurso amoroso fragmentado, se entrevé y se lee un erotismo contenido y latente a de su interlocución con hombres y mujeres. A unos y a otros les dedica bellas palabras y poemas para explicar sentimientos telúricos, carnales, donde lo corporal, lo sensual y lo espiritual se configura con palabras. Hay mucha poesía en su escritura.

No olvidemos que la historia de las mujeres del siglo XIX era muy segregada, las mujeres tenían que aliarse para poder hacer vida social, productiva, pública o intelectual. Incluso formaban sociedades femeninas mutualistas de mujeres para proveerse cuidados en la vejez. Estas sociedades no necesariamente eran homosexuales, muestran eso si la ausencia de un estado de derecho para las mujeres. Eran comunidades sororales para enfrentar el desamparo. Una gran cantidad de casos de mujeres intelectuales y viajeras, no tenían pareja y establecían alianzas sororales duraderas y fuertes con sus similares. El afecto incondicional entre amigas, escrito en los términos y convenciones del lenguaje de género del siglo XIX, es lo que quedó documentado en la biografía epistolar de la relación entre Palma y Gabriela. ${ }^{16}$

14 Sororal enuncia en primer término la posibilidad de las mujeres de ser hermanas, en términos de fraternidad, el feminismo estadounidense acuńó el término como sisterhood. Actualmente el feminismo reivindica las dimensiones éticas y políticas de la unión y ayuda entre mujeres para enfrentar la desigualdad y la discriminación.

15 Fiol-Matta, Lucía A Queer Mother for the Nation: The State and Gabriela Mistral. Minneapolis, Minn., University of Minnesota, 2002.

16 Recuérdese que los usos históricos del lenguaje amoroso se transformas. Por ejemplo el término "hacer el amor" en el siglo XIX era usado para referirse al cortejo y actualmente se usa para señalar una relación sexual. 


\section{Un epistolario sororal}

Se decían "hijitas", Palma era su "hijita querida”, y Palma se decía "tu Palma” para despedirse. En los usos coloquiales y populares en México, es común usar esos términos para expresar afecto y cuidado, entre familiares y mujeres. En el sureste mexicano, por ejemplo, las mujeres pueden decirse "mamita", "hijita", "manita", "linda", "bonita", "chiquita", "preciosa”, para suavizar más una conversación. Encuentro un uso muy mexicano, popular y sororal en el uso que Gabriela y Palma dan a esas maneras de escribirse y nombrarse.

Por lo demás, el contenido de las cartas confirma una poderosa amistad entre mujeres que dan peso a lo íntimo como importante.

Acompañaban las cartas con recortes de periódico sobre las vicisitudes de la guerra y con mil detalles sobre los cuidados de la salud, medicinas y noticias de las andanzas de las otras "amigas". Eventualmente con algún cheque-casi siempre Gabriela- para ayudar en los gastos, Nada de vanidad se percibe en su relación que pudiera denotar egos de divas o de mujeres con influencia en la literatura y la diplomacia. Aunque ciertamente cada una tenía sus espacios de poder público. Eso, lo público, es lo que aparecerá en los diarios o en las gacetas. En sus cartas se abordaba lo importante, la salud, los sueños, las añoranzas, sin el lustre del paso de la premio nobel por los diferentes foros del mundo. Incluso Gabriela se refiere al PN.

En las cartas se teje lo profundo de sentimientos y lealtades, los recuerdos buenos y hermosos de los viajes. Se habla también del oficio importante de la escritora, de las pérdidas de habilidades y capacidades, Gabriela que pierde papeles y libros y cheques y cartas entre tantas valijas. Además no deja de emprender grandes proyectos literarios o editoriales, para los que no tiene más que aceptar invitaciones a través de cartas.

En las cartas privadas se aborda lo privado, lo que duele lo que se añora y lo que no se dice en público. Gabriela es como la hermana mayor, aunque no la más fuerte, se conocen: Palma es una gran gestionadora de los asuntos de Gabriela, incluso estando en México sigue atendiendo por las vías diplomáticas, múltiples asuntos de la premio nobel. Fuera atendiendo asuntos de propiedades inmobiliarias o de propiedad intelectual.

Gracias a la publicación de las cartas que intercambiaron de 1942 a 1957 publicadas por Zegers, $(2001,2007,2009,2014)$ podemos conocer las cartas para recrear al detalle esta histórica amistad sororal. 


\section{Las cartas en el infortunio}

La mayor lealtad de Palma con Gabriela fue la de compartir la crianza de Yin Yin, sobrino de Gabriela y que Palma firmó en Tuición ante notario, para compartir los cuidados. Así lo hizo y en múltiples momentos aparece con YY en vacaciones y la vida doméstica.

Para ambas amigas era importante escribirse para contarse los sueños, especialmente le dice que ella que sueña poco, cuando sueña a Gabriela entra en una gran angustia por compartirlo todo:

\section{La Habana, agosto 17/942.}

Hijita querida:

He estado con mucha preocupación por ti estos últimos días porque te he soñado. Ya sabes: yo sueño raramente y cuando la gente me visita dormida por algo es. -Anoche mismo volvía a tenerte conmigo en el sueño: no se bien que era. Tú te ibas con otra persona dejándome a un lado sin hacerme caso; pero estabas contenta-: te oía -te oigo aún- reir alto- Antes de ayer fue otra cosa. Me sońé muerta, hijita. Estaba en tu casa contigo y con Yin Yin [hijo adoptivo de Gabriela] pero estaba muerta, y vosotros no me veíais- Hoy, al desayunarme, le dije a Luz [hermana de Palma] -Tengo miedo de que le pase algo a Gabriela -porque la he soñado tres noches seguidas [...]. Tengo muchas, muchas ganas de verte Chinita querida y de ver a ese sinvergüenza de Yin Yin. Cuida mucho tu salud, hijita, y procura no estar triste.. [...] (Firma: Te besa y te bendice... tu Palma) (ZEGERS, 2011,17).

$\mathrm{Al}$ año siguiente justo en agosto 14, Yin Yin el hijo adoptivo que Gabriela y Palma adoraban, se quitó la vida dejando en ellas una gran tristeza. Durante 1942 y 1943 , las cartas expresaban esa preocupación por atender y orientar al adolescente difícil. Gabriela entonces radicaba en Petrópolis, Brasil, ante la rebeldía del muchacho, había optado por meterlo a una escuela agrícola, para que se fortaleciera y se ocupara la mente en cosas prácticas. El chico expresaba que no le gustaba estar ahí, y para desconcierto de su madre, nada completaba y nada le gustaba, incluso llegó a consumir alcohol, lo cual en el marco disciplinario de la época era inaceptable.

Así, comparten las reflexiones y medidas para mejorar la crianza de Yin Yin al que a veces llama Juanito ${ }^{17}$, quien se encontraba indeciso de su orientación vocacional a los 18 años: 
La Habana, sept. 23/ 942.

Hijita linda y querida:

Acabo de recibir una carta de Juanito que me ha dejado una impresión muy penosa. Me habla en ella de su deseo de ser aviador y me ruega que no me oponga. Le he contestado lo que te contesté a ti a ese respecto: que no estaría mal que se hiciera hombre - que es lo primero que tiene que ser un aviador: hombre fuerte, disciplinado, firme y tranquilodedicándose a la aviación. [...] Que si tu lo has puesto en la escuela agrícola es porque quieres comprarle una finquita - no para que el trabaje directamente la tierra, sino para que la explote y la dirija. [...] Necesitas tener con él a la vez firmeza y ternura hijita, porque de ambas cosas necesita mucho - su carta está llena de rencorrencor contra ti, aunque no lo dice - contra los aduladores que te rodean (así dice) [...] La crisis de la adolescencia es siempre cosa muy seria, hijita, sobre todo cuando se tiene un temperamento nervioso y débil como es el caso de Juanito. [...] Me aflige no poder irme contigo enseguida contigo para ayudarte en este grave momento- [...] Te abrazo, mi pobrecita. Ten calma; firmeza y paciencia es lo que más necesitas en estos días - Te abrazo. Cada noche rezo por ti y por YY. Mil cariños y bendiciones de tu ... Palma. (ZEGERS, 2011,22)

Gabriela en sus cartas expresa también la demanda de apoyo de Palma para sacar adelante su trabajo cuando la abandona su secretaria Conie y no puede con el hijo,- confía en que a ella la escuche-, pues el chico incluso la asusta por su enojo y su rebeldía. Palma desde México y cuidando a su hermana Luz de un problema cardiaco, trata mediante cartas, apaciguar la situación en lo que logra por fin irse a Petrópolis.

Agosto 2/ 943.

Mi querido Juanito:

[...] Hijito querido, tu puedes ser la ayuda, el consuelo, la alegría y el descanso de tu mamita- selo. [...] Pronto llego yo, hijito, entretanto cuida a tu mamita como si fueras yo misma. ¡Por lo que más quieras! Dios te mira, Juanito mío querido - acuérdate y tenlo presente. Te besa y piensa siempre en ti tu ... Palmita. (ZEGERS, 2011, 43). 
El domingo 15 Palma envía una carta que expresa su total angustia por la crisis que pasa Gabriela:

Hijita estoy como si me hubieran dado un golpe en la cabeza: acabo de recibir tu cable puesto ayer 14 a la 14.13 en el que me dices tan solo: "Vente inmediatamente" -Qué pasa, qué pasa Dios Mío? - Si, Hijita, si, me iré en seguida _ es decir enseguida que pueda... mañana hipotecaremos la casa para tener dinero. Y mańana temprano iré a ver a Tello para que me pidan la prioridad en el avión por conducto de la Secretaría -Que la maleta grande se vaya por barco o que no se vaya _ Lo único que quiero ahora es saber qué pasa y estar contigo - ay si pudiera dormirme y amanecer alláii pero todo esto es imposible -Hay que hacer no se cuantas cosas y que hacerse pedazos de angustia en la oscuridad_Que pasa por Dios? Por qué no me dices siquiera una palabra para alumbrarme de algún modo? Voy a seguir con las maletas para dejar siquiera una terminada. Mi pobrecita qué te pasa? Estás enferma? Se porta mal Juanito?

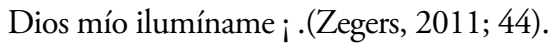

En esos momentos dolorosos Gabriela buscaba entender por qué Yin Yin se había quitado la vida. Ella desde meses atrás le había escrito a Palma que pensaba que andaban presionándolo otros chicos, para pedirle dinero y que todo esto era confuso. Pues el hijo estaba insoportable y deprimido. Ambas sabían de este carácter nervioso y difícil, pero además Gabriela percibía un ambiente fascista en la escuela que afectaba a los jóvenes.

Asimismo para Palma lograr todos los visados para llegar a Brasil era un ir y venir a oficinas para lograr 7 visas.

Martes 17 -19 horas

En este momento llega tu cable. Es verdad eso, Dios mío? Es juanito el enfermo? - Tengo ya cuatro visados, hijita mía, mi pobrecita? Mañana en la mañana tendré los otros tres, y... el dinero. Las maletas están casi terminadas y los papeles también -La prioridad me será dada también mañana. Hay aviones diariamente hijita, supongo que tomaré la vía pacífico porque, aunque más larga, es más rápida porque las prioridades se tienen con más facilidad -La maleta grande se irá en septiembre o cuando se pueda. Voy a seguir con los papeles para que mis cosas se queden en el mayor orden posible -Rezo por ti y por mi Yin Yin a toda hora. TU HIJITA PALMA. (Zegers, 2011; 43). 
Gabriela estuvo sumida en un profundo dolor por la pérdida de su Yin Yin, Palma la cuidó la reconfortó la cuidó, juntas rezaron y lloraron. Gabriela era nuevamente tocada por el infortunio y la muerte le arrebataba a otro ser querido. Palma se autonombra su hijita, la alienta a retomar la pluma a no perder la razón por tanto sufrimiento.

\section{Compartiendo la gloria}

Casi a finales de 1945, Gabriela Mistral es notificada de que le otorgarán el premio Nobel de Literatura. Un honor descomunal para la época por darlo a una mujer escritora, de América Latina. Palma le escribe emocionada:

\section{México, nov. 16/945.}

Mi Hijita querida:

Hoy en la mañana, temprano, me habla por teléfono Alfonso Reyes para darme la noticia de que te dieron- ipor fin!, el Premio Nobel - que te pusiera un cable de los dos diciéndote su gran alegría por la noticia. Estaba feliz y me dijo cosas preciosas de ti y de esa prosa tuya ue él adora y que es "como una brisa". Hijita querida, [...] hay como me duele no estar contigo, no haber sido yo quien te lleve los diarios con el cable a tu cama en la mañana; Dónde estás? En Petropolis? En Río? - [...] Hijita, ¿Qué es lo que hay que hacer con motivo del premio? Creo haberte oído decir que había que ir a Estocolmo [...] te abraza cien veces tu hijita que no te olvida un momento. PALMA. (Zegers, 2011;47).

Palma en México empezó a ser buscada para pedirle mediara con Gabriela Mistral, para homenajes y ediciones de libros. Ella recortaba las notas de los periódicos que hablaban del premio y los enviaba a Gabriela acompañando las cartas. También daba gracias a Dios "por este bien que te ha hecho" aunque tarde. No obstante a la par de hablar del Premio Nobel, (Gabriela lo nombró el PN) sin adulaciones, más era lo que hablaban de otras cosas domésticas y cotidianas, sobre la política en Brasil y en México. Palma representa a Gabriela en reuniones donde se lee su poesía, Junto a Carlos Pellicer, cuya amistad permanecía, ellos en Bellas artes, que la recibieron en el muelle, dos décadas atrás, mantenían la amistad y la lealtad a Gabriela, ahora si apabullada de aduladores. 


\section{Juntas en la enfermedad}

Los siguientes 12 años posteriores al premio nobel fueron confortable y difíciles para Gabriela, que a la par de ser muy influyente y muy solicitada, también resultó enfermar del hígado, la diabetes y el corazón. Contrayendo finalmente un cáncer de páncreas que le costó la vida en 1957. Los médicos más famosos del mundo la veían y el Dr. Chávez, destacado Cardiólogo, afirmaba que Gabriela tenía más bien soledad en su vida en los Ángeles.

Palma en estos años, realizaba labor consular intensa y tenía un trajín diplomático del que no hablaba mucho en las cartas, pero tiene muchos viajes, recepciones con embajadores y delegaciones diplomáticas. Es decir tiene puestos importantes. A la par también cuidaba de su esposo enfermo y de ella misma, con días buenos y otros no tanto. Gabriela que no paraba de recibir homenajes y dictar conferencias, siguió viajando mucho por un tiempo, además encontró nuevas aliadas y se trasladó a Nueva York, sólo en los últimos años ya no podía viajar tanto como antes, incluso aún no recuperaba sus libros de maletas y mudanzas anteriores. Pedía a Palma que le enviara libros en Español, que eran más fáciles de conseguir en México que en Estados Unidos. Consultaba médicos y compartía con Palma los detalles de medicamentos y de remedios. Compartes datos de su peso, sus niveles de azúcar y las vitaminas que están tomando. Palma por su parte le hacía llegar muchos libros, cartas en Español para que no lo olvidara y las buenas hierbas y remedios mexicanos, acompañados de cartas con muchos consejos de dietas y de ejercicios para la diabetes de Gabriela. La ayudaba a llevar las cuentas y a gestionar la renta de sus casas en Brasil y en Santa Bárbara.

Le recordaba la situación de cada amigo, le recomendaba a otros libros y escritores que esperan su aprobación y unas líneas para ayudarlos. Le recortaba información útil para su Poema de Chile, la gran obra de Gabriela.

\section{Las cartas poéticas de Gabriela}

Aún en los momentos de mayor trabajo y enfermedad y agotamiento. Gabriela y Palma tienen, momentos de intercambios de las cosas bellas, de añoranzas bien colocadas. En los últimos años de su vida Gabriela vivió en los Ángeles y luego en Long Island con Doris Dana, no dejaba por ello de escribirle a Palma, regalando algún trozo poético o de buena prosa. A veces daban por implícito el lugar y la fecha. Tiempo y espacio era para ellas parte de ese transitar por la amistad, pero ellas vivían la amistad a través de las cartas, así cuando Palma le recomienda pasear y acercarse al mar por sus efectos saludables, Gabriela le responde: 
1953

Querida mía:

Gracias por tu cartita, leída con doble gusto por nombrarme... al Mar mi marido! No sabía nada de eso del mar y ahora me da pena porque - no se si te lo dije - No me atrevo con Él. Yo te conté esto. Me puse a jugar con él y a decirle cosas y a la vez a echarle en cara, la gente que él ha ahogado! Y se me vino encima, Palma. Es cierto - tú has visto el pedazote que yo tengo de pagana. Lo tengo sin vuelta. Yo creo que todo ser con infancia en el campo no lo mira como - esa agua loca no mas, lo mira sin darse cuenta como "otra cosa", uno de los diocesitas de los antiguos. Yin me lo vio - todo veía él- y me lo dijo, y yo tuve que darle la razón, porque es verdad. [...] GAB. (Zegers, 2011; 306).

\section{A manera de conclusión, las cartas de pésame del pueblo}

En una carta de 1951 Palma expresó una frase significativa del alto poder de la intensa relación epistolar que tenía con Gabriela. "Y te escribo constantemente lo mismo cuando te tengo cartas tuyas que cuando no las tengo". Así es como las cartas trazan el repaso mental de amistad entre dos mujeres que compartieron la mejor y lo peor de la vida. Una amistad a ritmo epistolar, que se comunica y se piensa en formato epistolar.

Incluso al final fueron las cartas las que le revivían el amor a la poeta, dice Palma: "Cuando murió, de muchos de esos pueblos, recibí yo cartas de pésame de personas que, 35 años antes, la habían conocido y que me escribieron a mí porque no sabían si ella tenía aún familia”.

\section{Referencias}

ALEGRÍA, CIRO. 1989. Gabriela Mistral intima. Santiago de Chile: Antártica. BARROS VAN BUREN, MARIO. 1990. Historia diplomática de Chile 15411938 (actualizada a 1958). Santiago: Andrés Bello.

BARRY WILKINS DOUGLAS, 2015. Gabriela con valija diplomática. La génesis de la vida consular de Gabriela Mistral, CONTEXTOS, No 33, 113-123

FIOL-MATTA, LUCÍA, 2002. A Queer Mother for the Nation: The State and Gabriela Mistral, Minneapolis, Minn., University of Minnesota. 
GUILLÉN, PALMA 1988. “Gabriela Mistral (1922-1924)”, en Mistral, Lecturas para mujeres, México, Secretaría de Educación Pública.

GÓNGORA, MARÍA EUGENIA. (2004). Construcción del sujeto femenino en el diario y la carta de amor: Lily Ińiguez y Gabriela Mistral. Revista chilena de literatura, (64), 149-154. https://dx.doi.org/10.4067/S071822952004000100011

HORAN, ELIZABETH. 2009. "Una mixtura de calvario y arcadia: La Cónsul Gabriela Mistral en Portugal,1935-1937”. Anales de la Literatura Chilena Vol. 11: 13-43.

MORAGA VALLE FABIO, 2014, "Lo mejor de chile está ahora en México", ideas políticas y labor Pedagógica de Gabriela Mistral en México (1922-1924), El Colegio de México, Historia Mexicana, XIII: 3.

MUNIZAGA IRIBARREN, MIGUEL. 1935. "Vida y confesiones de Gabriela Mistral”. Familia Vol. 19: 28-29 y 75-76.

QUEZADA, JAIME, 1995. Gabriela Mistral, escritos políticos, Santiago, Fondo de Cultura Económica.

ROJO, GRÍNOR, 1997. Dirán que está en la gloria. Mistral, Santiago, Fondo de Cultura Económica.

SCARPA, ROQUE ESTEBAN.1977. Una mujer nada de tonta. Santiago: Andrés Bello.

TAGLE DOMÍNGUEZ, MATÍAS. 2002. Gabriela Mistral y Pedro Aguirre Cerda a través de su correspondencia privada (1919-1941), HISTORIA, Vol. 35: 323-408.

TEITElBOIM, VOLODIA. 1991. Gabriel Mistral, Pública y Secreta. México, Hermes.

MISTRAL, GABRIELA, Lecturas para mujeres, SEP, México 2. reimpresión, 1988. 496 p.

VIOLI, PATRIZIA. La intimidad de la ausencia: formas de la estructura epistolar. Revista de Occidente, 68 (1987): 90.

VIOLI, PATRIZIA. El infinito singular. Madrid: Cátedra, 1991.

VIOLI, PATRIZIA. La intimidad de la ausencia: formas de la estructura epistolar. Revista de Occidente 68 (1987): 87-99. 
ZEGERS, PEDRO PABLO, 2001. Recopilación de la obra mistraliana, 19021922, Santiago, RIL-Editores.

ZEGERS, PEDRO PABLO (Comp.). 2007. Gabriela Mistral y México, Santiago, RIL-Editores.

ZEGERS, P. (ed.) (2009). Gabriela Mistral, niña errante: cartas a Doris Dana. Santiago: Editorial Lumen. 